\title{
Impact of Social Media Advertisements on University Students
}

\section{Javeria Nazeer*}

Lahore Garrison University, Pakistan

\begin{abstract}
This study investigates the "Impact of social media advertisements on university students of Lahore". The main aim of this research was to find out the attitude and behavior change in university students of Lahore regarding advertisements on social media through KAP survey using questionnaire as a tool of data collection and stratified random sampling as technique. It covers demographic characteristics like gender and age group of the respondents. For age the researcher has selected Age group (18-25 y) as young adults and (26-35 y) as adult students because sample comprises of university students only, for gender researcher has selected male and female respondents. The research questions are "What is the attitude of users of social media towards advertisements?" and "To which extent users feel change in their behavior after encountering ads on their home page?" The data was analyzed through univariate and bivariate statistical procedures and results are presented in frequencies, cross tabs and findings of hypothesis testing through correlation. The findings exposed that user's exposure to social media advertisements leads them to attitude as well as behavior change in age group (26-35 y). Moreover, results also revealed that male students are more affected by exposure to social media ads than female students.
\end{abstract}

Keywords: Social media advertising; Exposure; Attitude; Behavior

\section{Introduction}

In this world, Life is difficult to consider without mass media. Media informs, entertain, aware and invade us. Media are one of the major factors of social change. New media certainly has its influence on society and culture. Social media evolution has deeply transformed the communication landscape picture [1]. Social media is the name of the social networking sites such as Facebook, Twitter, LinkedIn, Myspace and blogs, these websites are the important websites for companies so they can maintain direct relationships with their customers. Companies have built entire departments who design and control social media according to their companies needs and promotional activities. Social media is different from traditional media because it is generated by users of these websites and users have more control over its use and they also generate content by themselves at times. According to Tuten [2] if social media became a part of a promotional campaign it can increase the brand awareness and it can also improve its image and reputation. He has also mentioned that the traffic to a retail website can be increased, there could be an increment in the sales and overall basic advertisements strategy could be enhance. To conduct information searches about a product and to make purchasing decisions customers are attracting to several types of social media on internet [3,4]. A study by Shandana Zafar [5] has revealed that young consumers in Pakistan shows positive behavior towards ads shown in social media. This study concluded that to target young consumers social media can be used as an effective medium of advertising. According to Mehta [6] positive attitude of consumers toward social network advertisements can help consumers to recall the products or brands and influence their behavior. Wang and Sun [7] has studied Romanian population and concluded that Americans like to buy online but Romanians only like to click ads. which indicates Romanian's attitude towards online ads. This study focuses that user's positive attitude towards advertisements in social media has positive effect on their behavior change. According to a research conducted by Lukka and James [8] at university of Bangkok, male users of age 25-34 years old spend more time on facebook, don't get bothered by ads, and have a positive attitude towards facebook ads. Lukka and James [8] in a study revealed that products can be advertised through Facebook in a personalized manner. Advertisers while placing their ads on Facebook can customize their information to their specific audience. They can target individuals on basis of mutual interests and demographic information. Facebook has given them opportunity to reach their target audience through interesting and cost cutting way than traditional advertising medium. Different techniques are used by Facebook advertisers to effectively disseminate commercial information to influence buying decisions. Advertisers are offered smart advertising by Facebook which enable them to show all the information for their audience [9]. A study by Madden [10] suggested that the university students are an ideal sample population as they have mixture of opinion, which results from factors such as cultural background, different interests and the constant exposure to the internet due to the nature of today's education system. In his study Rubin has suggested that the main aim of the Uses and Gratification is to know the psychological needs which shape user's reason for using the media and to find out the reasons which motivate users to engage in certain media use behaviors for gratifications that satisfy their important needs, identify the effects of users media use". Preceding researchers have tried to explore the psychological and behavior aspect of Internet users to understand the motivations for Internet usage. According to Kaye and Johnson, "users of the Web are more actively involved and engaged in using the Internet because of its interactivity. According to Elaboration likelihood model motivation and processing ability determine attitude change.Petty and Cacioppo discovered, in contrast to social judgment-involvement theory, that high levels of involvement do not invariably decrease persuasion. ELM is mostly used in Advertising and psychological research. This theory integrates a range of variables into an explanation of persuasion. It deals with the elements that explains why and when messages are more or less likely to lead to attitude shaping. Lukka and James suggested that the Facebook users will have more positive attitude and advertisements will became more attractive to them

*Corresponding author: Javeria Nazeer, Assistant Professor, Lahore Garrison University, Pakistan, Tel: +92 42 37181821; E-mail: javerianazeer@Igu.edu.pk

Received July 30, 2017; Accepted August 06, 2017; Published August 14, 2017

Citation: Nazeer J (2017) Impact of Social Media Advertisements on University Students. Arts Social Sci J 8: 290. doi: 10.4172/2151-6200.1000290

Copyright: ( 2017 Nazeer J. This is an open-access article distributed under the terms of the Creative Commons Attribution License, which permits unrestricted use, distribution, and reproduction in any medium, provided the original author and source are credited. 
if they are recommended by a friend personally. Again if the user is following a company, the central route will be depicted, it means that the user has used careful conditions with this brand/product. When he came to interaction with the advertisements it would also lead to more positive attitude. In proposed research work the researcher has selected Facebook as ultimate social network because Facebook is most popular social networking site among Pakistani users. The research is basically on pattern of AIDA Model of advertising and KAP survey. After Wi-Fi revolution in Pakistan the quantity of social media users through new media technologies like android phones, iPad, tablets has increased. Samra Muslim has revealed that the most social media users use Facebook in Pakistan. In Dec 2011, Pakistan had 5.5million users on Facebook (largest social media network in Pakistan) by Jan 2013 Facebook users have grown to over 8 million users. The university level students are more vibrant users of Facebook. They have an age range from 18 to 35 (younger people to people entering in adulthood). They are the perfect population sample for analysis of social media advertisement's impact on users. In this research user's attitude and behavior was identified and composed in a conceptual framework. Research hypotheses were developed and, a survey among Facebook users was carried to formalize the framework.

\section{Statement of Problem}

This study aims to investigate the behavior of social media users towards targeted advertising on their homepage. It will measure the behavioral adaptations and changes in user's attitude towards these advertisements. There is a rise in advertisements of online social networks, and perception of users regarding targeted messages on popular network like Facebook is not known to greater extent. Marketers should be enabled to reach users with relevant advertisements and personalized messages. Such targeting will increase the value of advertising for both advertisers and social network users.

\section{Research Objectives}

Objectives of the study are:

To evaluate the impact of social media ads on its users.

To investigate the attitude of users of online social networks towards advertisements.

To explore and find out the behavioral changes in users of social media adds.

\section{Research Questions}

RQ1: What is the attitude of users of social media towards advertisements?

RQ2: To which extent users feel change in their behavior after encountering ads on their home page?

\section{Hypotheses}

H1: Exposure to social media advertisements leads to user's attitude.

H1A: Male users have more impact on their attitude than female users while exposure to social media advertisements.

H1B: Adults have more impact on their attitude as compared to young adults while exposure to social media advertisements.

$\mathrm{H} 2$ : Exposure to social media advertisements leads to user's behavior.
H2A: Male users have more impact on their behavior than female users while exposure to social media advertisements.

H2B: Adults have more impact on their behavior as compared to young adults while exposure to social media advertisements.

\section{Significance of the Study}

This study will help academic and commercial researchers to conduct their research on this new media advertising and its new dimension. The focus of the empirical study is to provide insights into user perception of Facebook advertising that may serve as a guideline for network operators and advertisers as well as a basis for further studies in this important area of research. The study will investigate the influence of advertisements on user's behavior and attitude formation.

\section{Research Design}

In this article, the researcher has applied the survey method to gather the quantitative data from a large representative but assorted population.

\section{Research Method}

\section{Survey}

In this research, the researcher has applied the survey method to gather the quantitative data from a large representative but assorted population. The survey method has helped researcher in collecting information directly from the university students that are using social media and affecting their shopping behavior in any way. The effects on the attitude and behavior of university students have hence sorted out through the information given on a quantitative scale. In this article, researcher has used questionnaire technique.

\section{Population, sample and sampling technique}

This study consists of a sample size of 300 respondents and stratified random sampling technique is used. Due to the budget and time limitations, only few universities (Kinnaird College For Women University, Lahore College For Women University, Government College University, Lahore Garrison University, Punjab University, University of Management and Technology, University Of Lahore, Lahore School of Economics, University of Central Punjab ) of Lahore city were covered in this the study. Total population of this research study comprises of all the University students aged 18 to 35 years, who have access to internet and residing in Lahore. It was not feasible for the researcher to approach the total population; therefore, sampling technique was applied. The rationale behind this selection is the variety among the participants studying in these universities and the researcher was able to study the impact of Facebook advertisements on the behavior of university students including young adults (18-25 y) and adult students (26-35 y) as well as male and female students.

\section{Variables of the Study}

Exposure to social media is independent variable and attitude and behavior variables are dependent variables. As the study based on KAP survey model, statements used as items to evaluate variables. To evaluate:

a) Exposure/knowledge variables are (Exposure to internet, Exposure to Facebook), to measure.

b) Attitude (Attraction for advertisements, Prejudgment for purchase, Share comments after a purchase, Relying on ad information, 
Uncomfortable on ad information), for Behavior (Trigger to purchase, Exposure making E-shopper, attitude change after reading comments, Feedback affect purchase, Feel encouraged to voice out opinion),

c) Demographic Variables are Gender and Age.

\section{Data Collection and Statistics Used}

In this research, a questionnaire was selected as a tool for data collection. In this study exposure to social media advertisements and its impact on attitude and behavior of university students' relationship was evaluated by correlation analysis. Correlation analysis measures the relationship between two items. When comparing the correlation between two items, one item is called the "dependent" item and the other the "independent" item. The goal is to see if a change in the independent item will result in a change in the dependent item In this article, the researcher has used Univariate and Bivariate analysis. The descriptive analysis section records the demography of the respondents and focuses on gender and age. Internet and especially social networking sites are widely used by young generation in Lahore and other urban areas due to easy internet access to internet at homes, offices and educational institutions.

\section{Data Analysis and Interpretations}

To examine the impact of social media advertisements on behavior and attitude of users, the researcher has selected sample having dissimilar demography. For this research, researcher has selected two demography of the sample gender and age. For age the researcher has selected two age groups young adults and adults, for gender, the researcher has selected male and female. Total sample population consists of 300 respondents. For demographic age 150 (50\%) were age group (18 to 25 years) young adults and $150(50 \%)$ were age group (2635 years) adults, for demographic gender 150 (50\%) were male and 150 $(50 \%)$ were female respondents.

\section{RQ1. What is the Attitude of Users of Social Media towards Advertisements?}

Table 1 shows that $7.7 \%$ respondents strongly disagree that they attract to Facebook advertisements where $14.0 \%$ disagree, 33\% remained neutral, $38 \%$ were agree and only $7.3 \%$ of them were strongly agree. When asked about prejudgment for purchase because of exposure to social media advertisements $0.7 \%$ respondents were strongly disagree about the statement, $12.3 \%$ were disagree, $34 \%$ were neutral $45.3 \%$ said they are agreed and $7.7 \%$ were strongly agree. $4.7 \%$ respondents said that they are strongly disagree that they share comments on social media after a purchase, $14 \%$ were disagree, 27.7 were neutral, $43.3 \%$ were agree to the statement and $10.3 \%$ were strongly agree.

$5.3 \%$ respondents strongly disagree that they rely on social media advertisements information about a product where $22.3 \%$ disagree, $30 \%$ remained neutral, $37.3 \%$ were agree and only $5 \%$ of them were strongly agree. When asked about uncomfortableness on social media ads information $5.7 \%$ respondents were strongly disagree about the statement, $14.7 \%$ were disagree, $33 \%$ were neutral $36.7 \%$ said they are agreed and $10 \%$ were strongly agree.

\section{H1: Exposure to social media advertisements leads to user's attitude}

Table 2 shows correlation between media exposure and attitude of the media user. As evident from the table exposure to internet was significantly correlated with prejudgment for purchase $(0.174$; $\mathrm{p}=0.003)$, share comments after purchase $(0.170 ; \mathrm{p}=0.003)$, relying on ad information $(0.160 ; \mathrm{p}=0.006)$, and uncomfortable on ad information $(0.174 ; \mathrm{p}=0.003)$ but there is no correlation was found between exposure to internet and attraction for advertisements $(0.074 ; \mathrm{p}=0.190)$. Similarly, relationship between exposure to Facebook was significantly found with all the attitudes of the users. Thus the hypothesis "exposure to online social network advertisements leads to user's attitude" was supported.

\section{H1A: Male users have more impact on their attitude than fe- male users while exposure to Social media advertisements}

Table 3 shows correlation between gender's media exposure and attitude of the social media user. As evident from the table male respondents exposure to internet is significantly correlated with uncomfortable on ad information $(0.233 ; \mathrm{p}=.004)$, sharing comments after purchase $(0.198 ; \mathrm{p}=0.015)$, but there is no correlation was found between male respondents exposure to internet and relying on ad information, attraction for advertisements and pre judgment for purchase. Similarly female respondents exposure to internet is significantly correlated with pre judgment for purchase $(0.220$ $\mathrm{p}=0.001)$, relying on ad information $(0.203 ; \mathrm{p}=0.013)$, but there is no correlation was found between female respondents exposure to internet and attraction for advertisements, uncomfortable on ad information and sharing comments after purchase. It is also evident from the table that male respondent's exposure to Facebook is significantly correlated with all the attitudes of users. Similarly female respondent's exposure to Facebook is significantly correlated with relying on ad information $(0.261 ; \mathrm{p}=0.001)$, pre judgment for purchase $(0.185 ; \mathrm{p}=0.023)$, but there

\begin{tabular}{|l|c|c|c|c|}
\hline Variables & Strongly disagree & Disagree & Neutral & Strongly agree \\
\hline Attraction for ads & $23(7.7 \%)$ & $42(14.0 \%)$ & $99(33.0 \%)$ & $114(38.0 \%)$ \\
\hline Prejudgment for purchase & $2(0.7 \%)$ & $37(12.3 \%)$ & $102(34.0 \%)$ & $136(45.3 \%)$ \\
\hline Sharing comments after purchase & $14(4.7 \%)$ & $42(14.0 \%)$ & $83(27.7 \%)$ & $130(43.3 \%)$ \\
\hline Relying on ad information & $16(5.3 \%)$ & $67(22.3 \%)$ & $90(30.0 \%)$ & $112(37.3 \%)$ \\
\hline Uncomfortable on ad information & $17(5.7 \%)$ & $44(14.7 \%)$ & $99(33.0 \%)$ & $110(36.7 \%)$ \\
\hline
\end{tabular}

Table 1: Frequency table for attitude of users towards social media ads.

\begin{tabular}{|c|c|c|c|c|c|}
\hline Media Exposure & Attraction for advertisements & $\begin{array}{l}\text { Pre judgment for } \\
\text { purchase }\end{array}$ & $\begin{array}{c}\text { Sharing comments after } \\
\text { purchase }\end{array}$ & Relying on Ad information & $\begin{array}{l}\text { Uncomfortable on Ad } \\
\text { information }\end{array}$ \\
\hline Internet & $076(190)$ & $174^{* *}(003)$ & $170^{\star *}(003)$ & $.160^{\star *}(.006)$ & $.174^{* *}(.003)$ \\
\hline Face book & $144^{*}(013)$ & $227^{\star \star}(000)$ & $196^{* *}(001)$ & $.226^{\star *}(.000)$ & $.162^{* *}(.005)$ \\
\hline
\end{tabular}

Note: N: 300

${ }^{\star *}$ Correlation is significant at the 0.01 level (2-tailed).

${ }^{*}$ Correlation is significant at the 0.05 level (2-tailed).

Table 2: Relationship between exposure and attitude of the media user. 


\begin{tabular}{|l|l|c|c|c|c|}
\hline Media Exposure & Gender & $\begin{array}{c}\text { Attraction for } \\
\text { advertisements }\end{array}$ & $\begin{array}{c}\text { Pre judgment for } \\
\text { purchase }\end{array}$ & $\begin{array}{c}\text { Sharing comments after } \\
\text { purchase }\end{array}$ & $\begin{array}{c}\text { relying on Ad } \\
\text { information }\end{array}$ \\
\hline Internet & Male & $073(.374)$ & $130(.013)$ & $198^{*}(.015)$ & $121(.141)$ \\
\hline Face book & Female & $085(.302)$ & $220^{* *}(.001)$ & $145(.076)$ & $233^{* *}(.004)$ \\
\hline & Male & $186^{*}(.023)$ & $291^{* *}(.000)$ & $303^{* *}(.000)$ & $203^{*}(.013)$ \\
\cline { 2 - 6 } & Female & $128(.120)$ & $185^{*}(.023)$ & $107(.191)$ & $202^{*}(.013)$ \\
\hline
\end{tabular}

$\mathrm{N}: 300$

${ }^{* *}$ Correlation is significant at the 0.01 level (2-tailed).

${ }^{*}$ Correlation is significant at the 0.05 level (2-tailed).

Table 3: Relationship between gender's exposure to media and attitude of the media user.

\begin{tabular}{|l|l|c|c|c|c|c|}
\hline Media Exposure & Age & $\begin{array}{c}\text { Attraction for } \\
\text { advertisements }\end{array}$ & $\begin{array}{c}\text { Pre judgment for } \\
\text { purchase }\end{array}$ & $\begin{array}{c}\text { Sharing comments } \\
\text { after purchase }\end{array}$ & $\begin{array}{c}\text { relying on Ad } \\
\text { information }\end{array}$ \\
\hline Internet & Young adult & $.067(.414)$ & $.087(.290)$ & $.144(.079)$ & $.097(.238)$ \\
& Adult & $.073(.372)$ & $.244^{* *}(.003)$ & $.181^{*}(.026)$ & $.210^{* *}(.010)$ \\
\hline Face book & Young adult & $.136(.097)$ & $.102(.215)$ & $.142(.084)$ & $.270^{* *}(.001)$ \\
\cline { 2 - 7 } & Adult & $.146(.075)$ & $.340^{* *}(.000)$ & $.240^{* *}(.003)$ & $.179^{* *}(.001)$ & $.176^{*}(.031)$ \\
\hline
\end{tabular}

Note:

$\mathrm{N}: 300$

${ }^{\star *}$ Correlation is significant at the 0.01 level (2-tailed).

${ }^{*}$ Correlation is significant at the 0.05 level (2-tailed).

Table 4: Relationship between exposure to social media according to Age and attitude of the media user.

is no correlation was found between female respondent's exposure to Facebook and attraction for ads, sharing comments after purchase and uncomfortable on ads information. Thus the hypothesis "Male users have more impact on their attitude than female users while exposure to social media advertisements" was supported.

H1B: Social media advertisements have more impact on attitude of adults as compared to young adults

Table 4 shows correlation between respondent's exposure to media according to age and attitude of the social media user. As evident from the table there is no correlation was found between young adults' exposure to internet and their attitude. But adult respondents internet exposure is significantly correlated with uncomfortable on ad information $(0.259 ; \mathrm{p}=0.001)$, pre judgment for purchase (244; $\mathrm{p}=0.003)$, relying on ad information $(0.210 ; \mathrm{p}=0.010)$, sharing comments after purchase $(0.181 ; \mathrm{p}=0.026)$, but there is no significant correlation found between adult respondent's internet exposure and attraction to Facebook advertisements. It is also evident from table that young adult's exposure to Facebook is significantly correlated with relying on ad information $(0.270 ; \mathrm{p}=0.001)$, but there is no correlation was found among young adults exposure to Facebook and other variables of attitude of the user. As table shows there was correlation found between adults exposure to Facebook and pre judgment for purchase $(0.340 ; \mathrm{p}=0.000)$, sharing comments after purchase $(0.240$; $\mathrm{p}=0.003)$, uncomfortable on ad information (0.215; $\mathrm{p}=0.008)$, relying on ad information $(0.176 ; \mathrm{p}=0.031)$, but there is no correlation was found between adults' exposure to Facebook and attraction to advertisements. Thus the hypothesis "social media advertisements have more impact on attitude of adult people as compared to young adults" has been supported.

RQ.2: To which extent users feel change in their behavior after encountering ads on their homepage? Frequency table for behavior of users towards social media ads

Table 5 shows that $2.0 \%$ respondents strongly disagree that the Facebook advertisements triggers them to purchase where $16.7 \%$ disagree, $27.7 \%$ remained neutral, $43.3 \%$ were agree and only $10.3 \%$ of them were strongly agree. When asked if exposure to advertisements is making them E-shopper, $3.7 \%$ respondents were strongly disagree about the statement, $19 \%$ were disagree, $27.7 \%$ were neutral $42.3 \%$ said they are agreed and $7.3 \%$ were strongly agree.3.3\% respondents reply to the statement that they feel change in their attitude after reading comments on social media in strongly disagree, $14 \%$ were disagree, $21 \%$ were neutral, $51.3 \%$ were agree to the statement and $10.3 \%$ were strongly agree. $4.7 \%$ respondents strongly disagree that any feedback on social media about a product by other users affect their purchase regarding a product where $8.7 \%$ disagree, $27.3 \%$ remained neutral, $47.7 \%$ were agree and only $11.7 \%$ of them were strongly agree. When asked if they feel encouraged to voice out opinion on social media regarding a product $3 \%$ respondents were strongly disagree about the statement, $10.7 \%$ were disagree, $35.3 \%$ were neutral $44 \%$ said they are agreed and $7 \%$ were strongly agree.

\section{H2: Exposure to social media advertisements leads to user's behavior}

Table 6 shows correlation between media exposure and behavior of the media user. As evident from the table exposure to internet was significantly correlated with attitude change after reading comments $(0.167 ; p=0.004)$, but there is no correlation was found between exposure to internet and other variables of behavior. Similarly, relationship between exposure to Facebook was significantly correlated with exposure making E-shopper $(0.163 ; \mathrm{p}=0.005)$, ads trigger to purchase $(0.147 ; \mathrm{p}=0.011)$ attitude change after reading comments (0.146; $\mathrm{p}=0.011)$, feedback affect purchase $(0.118 ; \mathrm{p}=0.042)$, but there is no correlation was found between exposure to Facebook and feel encouraged to voice out opinion. Thus the hypothesis "exposure to social media advertisements leads to user's behavior" was supported.

\section{H2A: Male users have more impact on their behavior than female users while exposure to social media advertisements}

Table 7 shows correlation between gender's media exposure and behavior of the social media user. As evident from the table there is no correlation between male respondent's exposure to internet and behavior of the user. Similarly female users exposure to internet is 


\begin{tabular}{|l|c|c|c|c|c|}
\hline Variables & Strongly disagree & Disagree & neutral & Agree & Strongly agree \\
\hline Ads Triggers to purchase & $6(2.0 \%)$ & $50(16.7 \%)$ & $83(27.7 \%)$ & $130(43.3 \%)$ & $31(10.3 \%)$ \\
\hline Exposure Making more E-shopper & $11(3.7 \%)$ & $57(19.0 \%)$ & $83(27.7 \%)$ & $127(42.3 \%)$ & $22(7.3 \%)$ \\
\hline $\begin{array}{l}\text { Attitude change after reading } \\
\text { comments }\end{array}$ & $10(3.3 \%)$ & $42(14.0 \%)$ & $63(21.0 \%)$ & $154(51.3 \%)$ & $31(10.3 \%)$ \\
\hline Feedback affect purchase & $14(4.7 \%)$ & $26(8.7 \%)$ & $82(27.3 \%)$ & $143(47.7 \%)$ & $35(11.7 \%)$ \\
\hline Feel Encouraged to voice out opinion & $9(3.0 \%)$ & $32(10.7 \%)$ & $106(35.3 \%)$ & $132(44.0 \%)$ & $21(7.0 \%)$ \\
\hline
\end{tabular}

Table 5: Frequency table for behavior of users towards social media ads.

\begin{tabular}{|c|c|c|c|c|c|}
\hline Media Exposure & Ads Trigger to purchase & $\begin{array}{c}\text { Exposure making } \\
\text { E-shopper }\end{array}$ & $\begin{array}{c}\text { Attitude change After reading } \\
\text { comments }\end{array}$ & $\begin{array}{c}\text { Feedback affect } \\
\text { purchase }\end{array}$ & $\begin{array}{c}\text { Feel encouraged to voice } \\
\text { out opinion }\end{array}$ \\
\hline Internet & $110(.057)$ & $074(.200)$ & $.167^{\star *}(.004)$ & $.068(.238)$ & $.085(.140)$ \\
\hline Face book & $147^{\star}(.011)$ & $163^{\star *}(.005)$ & $.146^{\star}(.011)$ & $.118^{\star}(.042)$ & $.094(.105)$ \\
\hline
\end{tabular}

Note: N: 300

${ }^{* *}$ Correlation is significant at the 0.01 level (2-tailed).

${ }^{*}$ Correlation is significant at the 0.05 level (2-tailed).

Table 6: Relationship between exposure and behavior of the media user.

\begin{tabular}{|l|l|c|c|c|c|}
\hline Media Exposure & Gender & $\begin{array}{c}\text { Ads Trigger to } \\
\text { purchase }\end{array}$ & $\begin{array}{c}\text { Exposure making } \\
\text { E-shopper }\end{array}$ & $\begin{array}{c}\text { Attitude change } \\
\text { After reading } \\
\text { comments }\end{array}$ & $\begin{array}{c}\text { Feedback affect } \\
\text { purchase } \\
\text { voice out opinion }\end{array}$ \\
\hline Internet & Male & $0.68(.411)$ & $.052(.527)$ & $.129(.115)$ & $.078(.341)$ \\
\hline Face book & Female & $.171^{*}(.036)$ & $.092(.260)$ & $.210^{*}(.010)$ & $.059(.474)$ \\
& Male & $.194^{*}(.017)$ & $.199^{*}(.014)$ & $.182^{*}(.026)$ & $.110(.179)$ \\
\hline & Female & $.115(.161)$ & $.104(.206)$ & $.110(.179)$ & $.134)$ \\
\hline
\end{tabular}

Note: N: 300

${ }^{* *}$ Correlation is significant at the 0.01 level (2-tailed)

${ }^{*}$ Correlation is significant at the 0.05 level (2-tailed).

Table 7: Relationship between gender's exposure to media and behavior of the media user.

\begin{tabular}{|c|c|c|c|c|c|c|}
\hline Media Exposure & Age & $\begin{array}{l}\text { Ads Trigger to } \\
\text { purchase }\end{array}$ & $\begin{array}{c}\text { Exposure making } \\
\text { E-shopper }\end{array}$ & $\begin{array}{l}\text { Attitude change } \\
\text { After reading comments }\end{array}$ & $\begin{array}{c}\text { Feedback affect } \\
\text { purchase }\end{array}$ & $\begin{array}{l}\text { Feel encouraged to } \\
\text { voice out opinion }\end{array}$ \\
\hline \multirow[t]{2}{*}{ Internet } & Young adult & $.065(.428)$ & $.051(.536)$ & $.105(.199)$ & $.027(.743)$ & $.005(.949)$ \\
\hline & Adult & $.277^{* *}(.01)$ & $.176^{*}(.031)$ & $.221^{\star *}(.007)$ & $.171^{*}(.037)$ & $.165^{\star}(.044)$ \\
\hline \multirow[t]{2}{*}{ Face book } & Young Adult & $.050(.545)$ & $.144(.079)$ & $.012(.886)$ & $.037(.653)$ & $-.020(.813)$ \\
\hline & Adult & $.331^{* *}(.00)$ & $.178^{*}(.029)$ & $.259^{\star *}(.001)$ & $.198^{*}(.015)$ & $.206^{*}(.012)$ \\
\hline
\end{tabular}

Note: $\mathrm{N}: 300$

${ }^{* *}$ Correlation is significant at the 0.01 level (2-tailed).

${ }^{*}$ Correlation is significant at the 0.05 level (2-tailed).

Table 8: Relationship between exposure to media according to age and behavior of the media user.

correlated with change in attitude after reading comments $(0.210$; $\mathrm{p}=0.010)$,Ads trigger to purchase $(0.171 ; \mathrm{p}=0.036)$ but there is no correlation was found between female respondents exposure to internet and exposure making E-shopper, feedback affect purchase and feel encouraged to voice out opinion.

It is also evident from the table that male respondent's exposure to Facebook is significantly correlated with feel encouraged to voice out opinion (0.227; $\mathrm{p}=0.005)$, exposure making E-shopper (0.199; $\mathrm{p}=0.014)$, trigger to purchase $(0.194 ; \mathrm{p}=0.017)$ change in attitude after reading comments $(0.182 ; \mathrm{p}=0.026)$, but there is no correlation was found between male respondent's exposure to Facebook and feedback affect purchase. Similarly there is no correlation was found between female's exposure to Facebook and variables of behavior in media user. Thus the hypothesis "Male users have more impact on their behavior than female users while exposure to social media advertisements" is supported.

H2B: Adults have more impact on their behavior than young adults while exposure to social media advertisements

Table 8 shows correlation between respondent's exposure to media according to age and behavior of the social media user. As evident from the table there is no significant correlation was found between young adults' exposure to internet and their behavior. But there is significant correlation between adult user's exposure to internet and their behavior. It is also evident from table that there is no significant correlation between young adults' exposure to Facebook and their behavior, but adults' exposure to Facebook has significant correlation with the behavior of the social media user. Thus the hypothesis "social media advertisements have more impact on behavior of adults as compared to young adults" has been supported.

\section{Findings and Discussion Analysis}

The basic objective of this research was to study the impact of social media advertisements on attitude and behavior of University students. Therefore, this research tried to identify whether advertisements on social media has any impact on its users attitudes and behaviors. The study produced results by comparing diverse demographic variables and operationalization of exposure as independent variable and use of KAP survey model. Internet and social media is commonly used by students of universities in Lahore. Because of the easy access to internet social media i.e. social networking sites are getting very popular 
among people. Moreover, this study presented the data according to age and gender. The hypothesis of study included exposure to social media advertisements leads to user's attitude and behavior. It has subhypotheses which state that exposure to social media ads has impact on male users than female users. As male percentage of social media users in Pakistan is higher than female users. Male users are more financially independent and also they don't have to face any barriers or restrictions as females has to face in Pakistani society. Another subhypothesis stated that the adults have more impact than young adults while exposure to social media ads. As adults are more financially independent and they have settled their careers to somehow, moreover, their attitudes are more serious and they behave accordingly. But younger people are not much financially independent and they use social media just for socializing. All above mention factors were based on the conclusion drawn after reviewing the relevant literature as most of the studies were of the view that social media ads has impact on users behavior but according to age group, gender, culture and economic perspective. A study by louis Kelly and Gayle revealed the fact that young people avoid advertisements on social media rather focusing on socializing and making friends. Lukka and james [8] revealed in their study that male users of age group 25-35 have a more positive attitude towards Facebook advertisements. As study by Mir [11] has also shown in Pakistani perspective that knowledge and economy are statistically important forecasters of consumer attitude towards social media advertisements.

\section{Conclusion and Recommendations}

Though social media has grown globally in recent years and it has revolutionary impact on its user's attitude and behavior, but research is at exploratory level in this field from advertising point of view especially in developing countries like Pakistan. Major studies in this regard were conducted in developed and western countries. Current research tries to examine advertising in social media and user's behavior according to Pakistan's perspective. The main objective of this study is to examine user's beliefs/perceptions about social media ads specially Facebook and their effects on attitudes as well as behaviors. Wang and Sun [7] has studied Romanian population and concluded that Americans like to buy online but Romanians only like to click ads. Which indicates Romanian's attitude towards online ads. Current study also found this cultural pattern that most of the young students and female students don't go for online shopping and they don't get much effected by ads on social media. Their attitude might get influenced but they don't behave accordingly and go for a purchase because of economic, social and cultural limitations. Present research makes its contribution in advertising research. It affirms that user's attitudes and behaviors get influenced due to social media ads. According to some previous studies $[7,12]$ perceptions and attitudes are significant constructs of online ads. In social media context previous studies when examining consumer attitude towards ads apply method of qualitative interview for their research, face problem of generalizability [13-15]. Most of social media ads related research work belong to western countries but current study provides the Facebook users insights from an economic, social and cultural context of Pakistan $[16,17]$. The findings of this research work is useful for advertising firms, brands and companies, who want to advertise through social media in the collectivistic culture of developing countries like Pakistan. The study has its limitations. It only observes the user's attitudes and behaviors toward social media ads with reference to demographic gender and age in university level [18-20]. In future research income and lifestyle dimensions along with different age groups and professional fields of social media user should be examined. Moreover, current study has collected data from university students only, professionals and other walks of life populations' behavior toward social media advertising also need to be addressed.

\section{References}

1. Edwards SM (2011) A social media mind-set. J Interactive Advertising 12: 1-3.

2. Tuten LT (2008) Advertising 2.0: Social Media Marketing in a Web 2.0 Worlds.

3. Lempert $P$ (2006) Caught in the Web. Progressive Grocer 85: 18.

4. Vollmer C, Precourt G (2008) Always on: Advertising, marketing, and media in an era of consumer Control.

5. Zafar S, Majid KM (2011) Examining the attitude towards social network advertising: A study of young Pakistani consumers. International $\mathrm{J}$ academic research 3: 4 .

6. Mehta A (2000) Advertising Attitudes and Advertising Effectiveness. J Advertising Res 40: 67-72.

7. Wang Y, Sun S (2010) Assessing Beliefs, Attitudes, and Behavioural Responses toward Online Advertising in Three Countries. Int Bus Rev 19: 333-344.

8. Lukka V, James PTJ (2014) Attitudes toward Facebook advertising. J Manag and Market Res 14: 1-26.

9. Mathieson R (2010) On-Demand Brand: 10 Rules for Digital Marketing Success in an Anytime, Everywhere World.

10. Madden M (2010) Older Adults Media and Social. (Retrieved August 2011).

11. Mir I, Zaheer A (2012) Verification of Social Impact Theory Claims in Social Media Context. J Internet Banking and Comm 17: 1-15.

12. Azeem A, Haq Z U (2012) Perception towards Internet Advertising: A Study with Reference to Three Different Demographic Groups. Global Bus and Manage Res: An Int J 4: 28-45.

13. Kelly L, Kerr G, Drennan J (2010) Avoidance of advertising in social networking sites: The Teenage perspective. J Interactive Advertising 10: 16-27.

14. Drury G (2008) Opinion piece: Social media: Should marketers engage and how can it be done effectively? J Direct, Data and Digital Market Practice 9 : 274-277.

15. Kaplan AM, Haenlein M (2010) Users of the World, Unite! The Challenges and Opportunities of Social Media. J Bus Horizons 53: 59-68.

16. Kaye BK, Johnson TJ (2004) A web for all reasons: uses \& gratifications of Internet resources for Political information.

17. Petty RE, Cacioppo JT (1986) The elaboration likelihood model of persuasion Advances in exp soc psycho 19: 123-205.

18. Rashtchy S, Kessler AM, Bieber PJ, Shindler NH, Tzeng JC (2007) The user revolution: The new advertising ecosystem and the rise of the Internet as a mass medium

19. Minnea polis, MN: Piper Jaffray Investment Research Statistics Canada Retrieved on $15^{\text {th }}$ march 2015.

20. Sandberg S. (2010) The Role of Advertising on Facebook. 